\title{
INFLUENCE OF MICROBIOTA ON THE CLINICAL AND IMMUNO- HISTOCHEMICAL CHARACTERISTICS OF CHRONIC GENERALIZED CATARRHAL GINGIVITIS IN CHILDREN
}

10.36740/WLek202101107

\author{
Tatiana V. Polishchuk, Natalia M. Lokhmatova, Olha V. Sheshukova, Irina M. Tkachenko, Sofia S. Bauman, \\ Alina I. Maksymenko \\ UKRAINIAN MEDICAL STOMATOLOGICAL ACADEMY, POLTAVA, UKRAINE
}

\begin{abstract}
The aim: The purpose of the study is to characterize the influence of quantitative and qualitative composition of gingival microbiota on the status of the main immune system cells, localized in the gums, in chronic generalized catarrhal gingivitis in children.

Materials and methods: The study involved 26 children aged 9 to 16 years, patients with chronic generalized catarrhal gingivitis mild to moderate severity (CGCG) and 18 children with intact gums were comparison group. We determined the hygienic indices Fedorov, has been received, Silness-Loe, PMA, bleeding index for Myuleman and intensity of caries index CFD + Cf, CFD. Histological and immunohistochemical studies were performed on serial sections kriostatnyh who made biopsy of gingival papillae. Microbiological study gingival part of crown plaque was performed by multiplexed PCR in real time.

Results: Value hygienic indices in children with $G G G$ higher than in healthy, indicating the difficulty of care in the presence of periodontal inflammation.

As a result of immunohistochemical studies revealed that HLA-DR + cells under conditions of active disease migrate to mucosal lamina propria epithelium. Number of CD3 + cells in the epithelium CGCG was significantly higher than the number in the intact epithelium and was the most numerous of population. In the biopsy of affected children significantly reduced the number of CD4 + cells. When CGCG quantitative total bacterial mass, Lactobacillus spp., Enterobacteriaceae, Gardnerella vaginalis / Prevotella bivia / Porphyromonas spp. in the sample CROWN dental plaque was significantly higher than rates under physiological conditions, and may serve as diagnostic criteria of dysbiosis. Conclusions: So, CGCG is a disease in the etiology of which is one of the leading roles played by microbial factor, namely, the value of the quantitative ratios of certain types of microorganisms of dental plaque compared to the total bacterial mass of plaque. Therefore, it is reasonable to include comprehensive treatment CGCG drugs in children, leading to natural immunostimulation which causes restoration of local immunity in the gum tissue and drugs to restore quantitative and qualitative composition of normal microflora of the child, thus providing a high therapeutic effect and serve as justification their choice.
\end{abstract}

KEY WORDS: children, chronic generalized catarrhal gingivitis, samples of gingival tissues, plaque microbial composition

Wiad Lek. 2021;74(1):39-42

\section{INTRODUCTION}

Chronic catarrhal gingivitis is currently considered as one of commonly spread oral disease. This disease can result from poor oral hygiene and be regarded as the first stage in the development of periodontitis or periodontal syndrome $[1,2]$. The risk factors for chronic catarrhal gingivitis typically include poor oral hygiene and some systemic disorders, but changes in the supragingival plaque microbiota structure just above the gingival margin play a leading etiological role [3-5].

The relevance of studies of immune cells, mucosal immunity in chronic catarrhal gingivitis is based on the fact that it is the immune response that is intended to protect, can support inflammation and trigger a cascade of destructive processes towards the body's own tissues [6]. The involvement of the main immune cells of the adaptive immunity in the lesion foci and their role are not completely understood and require detailed investigation of their susceptibility to various factors, and, in particular, their responsiveness to standard and novel therapy methods.

\section{THE AIM}

The purpose of the study is to characterize the influence of quantitative and qualitative composition of gingival microbiota on the status of the main immune system cells, localized in the gums, in chronic generalized catarrhal gingivitis in children.

\section{MATERIALS AND METHODS}

The clinical study included 26 paediatric patients aged from 9 to 16 years with chronic generalized catarrhal gingivitis of mild and moderate severity according to the classification recommended by the Republican Conference of Dentists of Ukraine (Odessa, 1998), and 18 children in good general health with intact gums, who made up the control group. 
All studies were conducted after the signing of the informed consent by patients. The study was approved by the Commission on Ethical Issues and Bioethics of Ukrainian medical stomatological academy.

Clinical dental examination, the establishment of diagnosis of chronic generalized mild or moderate catarrhal gingivitis and its confirmation were performed by using standard techniques [7]. The following clinical indices were assessed: the Fedorov-Volodkina hygienic index (1971), the Silness-Löe plaque index (1967), the PMA, the Muellemann bleeding index, and the caries intensity according to the DEF+df and DEF index.

The first group, a control group $(n=18)$, included individuals with intact gums. Quantitative and qualitative characteristics of gingival microbial plaque were studies in 10 subjects; histological and immunochemical study of gum papillae samples taken from the other 8 individuals were carried out as well.

The second group $(n=26)$ involved patients with chronic generalized catarrhal gingivitis of mild and moderate severity.

Histological and immunohistochemical studies were performed on serial cryostat sections, which were made from $2 \mathrm{~mm}^{3}$ gum samples obtained under conduction anaesthesia (Sol. Lidocaini 2\% 1.5-2.0 ml) from 8 subjects of the control group.

To determine the bacteria present in the supragingival plaque, we studied samples taken from the precervical segment of vestibular surface of two or three front teeth (incisors and canines) close to the gum margin on the upper and / or lower jaws.

\section{RESULTS}

Data collected on the oral hygienic status in both the individuals with intact parodontium and in the individuals with chronic generalized catarrhal gingivitis demonstrated its low level. It should be noted that the values of oral hygienic indices in the children with chronic generalized catarrhal gingivitis were higher than in the control that indicates the difficulty in keeping oral care in the presence of parodontium inflammation.

Findings of the dental examination of the children in the first group showed that their gums were pink, moist, shiny, gum papillae were point-ended, densely adhered to the teeth. Caries indexes corresponded to three degrees of the caries intensity.

The results of the periodontal tissue study showed that the PMA index, bleeding index, and Silness-Loe gingivitis index equalled 0 indicating no inflammation in the gums. The absence of chronic inflammation in the gums was confirmed by the negative results of the Pisarev-Schiller test.

The investigation of the morphological structure of the intact papilla showed that the condition of the mucous membrane was in line with the normal values. Immunohistochemical studies revealed that HLA-DR+ cells were located in the spinous layer, where they had numerous processes oriented mainly along the surface of the epithe- lium. While approaching the basement membrane, the cells lose their processes. These morphological changes reflect the trajectory of the movement of HLA-DR + antigen presenting cells represented by Langerhans cells in the oral mucosa.

An analysis of the $\mathrm{CD} 3$ + cells location revealed that their population was not numerous and represented by single cells located within the basal and adjacent spinous layers and in the lamina propria close to the basement membrane. The location and the number of CD4+ cells, in general, were identical to those of CD3+ cells; at the same time CD8+ cells were localized mainly in the projection of the papillae apices in the basal and adjacent spinous layers. CD20+ cells were single and rarely found in the basal and spinous layers, more often in the deep mucosa layers.

Histological examination of the gingival samples of the children with chronic generalized catarrhal gingivitis revealed manifestations of vacuolar epithelium $(25 \%$ balloonign dystrophy), parakeratosis (88\%), edema, and round-cell infiltration of the lamina propria (75\%).

Clinical findings in the patients of the second group demonstrated the following: gingival margin and interdental papillae were hyperemic, with cyanotic tinge, swollen, bleeding. The caries indices corresponded to the compensated and subcompensated forms of caries; hygienic condition in $75 \%$ of the patients with chronic generalized catarrhal gingivitis was unsatisfactory (2.1 to 5 points), PMA indexes (17\% to 50\%) and Caries Index (0.3 to 3.0) showed moderate gum inflammation.

Real-time PCR data have revealed that in chronic generalized catarrhal gingivitis, quantitative indicators of total bacterial mass, Lactobacillus spp., Enterobacteriaceae, Gardnerella vaginalis / Prevotella bivia / Porphyromonas spp. in the samples of supragingival plaque significantly exceed the indicators in health (physiological conditions), therefore they can serve as criteria for the diagnosis of dysbiosis (Table I).

It should be pointed out that in chronic gingivitis the total number of Lactobacillus spp. is significantly higher than that in the intact gums.

\section{DISCUSSION}

Immunohistochemical study has demonstrated HLA-DR+ cells in the disease actively migrated from the mucous membrane to the epithelium that was confirmed by a significant $(p<0.05)$ increase in their number in the epithelium and a decrease in their lamina propria. The number of CD3 + epithelial cells in chronic generalized catarrhal gingivitis was significantly higher than the number in intact epithelium and constituted the largest share of the population. The count of CD4+ cells in the samples of the second group showed a probable $(\mathrm{p}<0.05)$ decrease in the number of these cells in the epithelium and in their lamina propria. Thus, it can be assumed that in chronic generalized catarrhal gingivitis the regulatory potential of $\mathrm{CD} 4+$ cells gets impaired. Instead, we observed a redistribution of 
Table I. Indicators of dysbiosis in supragingival plaque in chronic generalized catarrhal gingivitis $\mathrm{M} \pm \mathrm{m}$

\begin{tabular}{ccccc}
\hline $\begin{array}{c}\text { Study } \\
\text { subjects }\end{array}$ & $\begin{array}{c}\text { Total bacterial } \\
\text { mass }\end{array}$ & Lactobacillus spp. & Entero-bacteriaceae spp. & $\begin{array}{c}\text { G.vaginalis/P.bivia / } \\
\text { Porphyromonas spp. }\end{array}$ \\
\hline I group & $6,38 \pm 0,45$ & $5,1 \pm 1,4$ & $5,1 \pm 0,44$ & $5,01 \pm 0,68$ \\
\hline II group & $7,56 \pm 0,3^{*}$ & $6,22 \pm 0,72^{*}$ & $6,22 \pm 0,2^{*}$ & $3.50 \pm 0,33^{*}$ \\
\hline
\end{tabular}

* - reliable difference between groups makes up $p<0,05$.

CD8+ cells, in which their presence in the lamina propria grew against a moderate decrease in their number in the epithelium. CD8+ cells perform predominantly effector / cytotoxic functions, and their accumulation in the epithelium indicates involvement of these cells in the immune response within the epithelium. The study of the CD20+ cell content revealed their number remained virtually unchanged. Thus, the processes occurring in the tissues of the gums in chronic generalized catarrhal gingivitis are consistent with the immune response of the cytotoxic type that undoubtedly indicates the necessity to use agents directed at eliminating the microbial factor [6].

The clinical significance of dysbiosis in the gingival plaque of consisted in denoting the correlation between clinical indices for chronic generalized catarrhal gingivitis and quantitative microbiota ratios. Thus, the results of statistical analysis using the Spearman nonparametric correlation test showed that quantitative indicators of $\mathrm{Lac}$ tobacillus spp. and Candida spp. were negatively correlated $(\mathrm{p}<0.05)$ with the Fedorov-Volodkina hygiene index $(\mathrm{R}=$ $-0.85 ; \mathrm{R}=-0.66$, respectively) in chronic generalized catarrhal gingivitis [3].

In chronic generalized catarrhal gingivitis, we have found out significant correlations $(\mathrm{p}<0.05)$ between the Silness-Loe hygiene index and the Eubacteridacea spp., $(\mathrm{R}=$ $0.60)$, and the negative correlation between the bleeding index and Lactobacillus spp. $(\mathrm{R}=-0,85)$. According to the relevant report $[3,8]$, this may reflect the value of $E \mathbf{u}$ bacteridacea spp. as an indicator of an increase in the total plague amount, and the predominance of autochthonous commensal species among Lactobacillus spp.

\section{CONCLUSIONS}

Thus, chronic generalized catarrhal gingivitis can be regarded as a disease, in aetiology of which a microbial factor and, namely, the value of the quantitative ratio of certain types of microorganisms in the supragingival plaque compared with the total bacterial mass of dental plaque plays a leading role. Accordingly, the action of microbial pathogens disrupts the barrier function of the epithelium and induces immunological responses in the mucous membrane, and the main effector processes take place within the epithelium, involving HLA-DR +, CD3 +, $\mathrm{CD} 4+, \mathrm{CD} 8+$ cells.

It is these characteristics that determine the reversibility of these pathological changes when using etiotropic therapy (antiseptic agents). However, using exclusively antiseptics leads to a sharp decrease in the degree of antigenic immu- nostimulation and microbiological parameters. Therefore, it seems to be appropriate to include medications resulting in the natural immunostimulation, which, in turn, promotes the local immunity recovery in gingival tissues, as well as medication restoring quantitative and qualitative microbiota structure, into the integrated therapy of chronic generalized catarrhal gingivitis in children.

\section{REFERENCES}

1. Polishchuk T.V., Trufanova V.P., Shynkevitsh V.I. Profilaktyka dysbioziv porozhnyn rota u ditey pry hinhivitakh [Prevention of oral dysbiosis in children with gingivitis]. Actual problems of modern medicine. 2010; 4 (32):243-246. (in Ukrainian).

2. Kosenko K.N., Den'ga 0.V., Khomenko L.A. Uroven' i struktura stomatologicheskoy zabolevayemosti u detey g. Kiyeva [The level and structure of dental disease in children in Kyiv]. Visnyk stomatologiyi. 2004; 4:79. (ia Russian).

3. Polishchuk T.V., Skrypnikov P. N., Kaidashev I. P. Diahnostyka dysbiozu pry khronichnomu kataral'nomu hinhiviti metodom mul'typleksnoyi polimeraznoyi lantsyuhovoyi reaktsiyi z reyestratsiyeyu danykh v real'nomu chasi [The diagnostics of dysbiosis at the chronic simple marginal gingivitis assessed by real-time polymerase chain reaction]. Actual problems of modern medicine. 2012;1-2 (37-38): 57-61. (in Ukrainian).

4. Rüdiger S.G., Carlén A., Meurman J.H. et al. Dental biofilms at healthy and inflamed gingival margins. J Clin Periodontol. 2002;6: 524-533.

5. Signoretto C., Bianchi F., Burlacchini G. et al. Drinking habits are associated with changes in the dental plaque microbial community. J Clin Microbiol. 2010; 48(2): 347-356.

6. Kaidashev I.P. Shinkevich V.I., Korol D.M. et al. Ocherki immunobiologii slizistoy obolochki polosti rta [Essays on the immunobiology of the oral mucosa]. Geneva: 1989:62. (in Russian).

7. Dal Bello F., Hertel C. Oral cavity as natural reservoir for intestinal lactobacilli. Syst Appl Microbiol. 2006;29 (1):69-76.

The work is a part of initiative research project "Investigation of pathogenetic mechanisms of the commonest childhood diseases, optimization of their diagnosis and treatment" carried out at the Department of Paediatric Dentistry, Ukrainian Medical Stomatological Academy, Registration Number 0117 U004683.

\section{ORCID and contributionship:}

Tatiana V. Polishchuk: 0000-0003-1114-5830 B,C,D

Natalia M. Lokhmatova: 0000-0002-7800-0516 ${ }^{B, C, D}$

Olha V. Sheshukova: 0000-0002-4739-4890 ${ }^{A, F}$

Irina M. Tkachenko: 0000-0001-8243-8644 ${ }^{E, F}$

Sofia S. Bauman: 0000-0002-9029-8968 B,C

Alina I. Maksymenko: 0000-0002-9791-0873 B,C 


\section{Conflict of interest:}

The Authors declare no conflict of interest.

\section{CORRESPONDING AUTHOR}

\section{Tatiana V. Polishchuk}

Ukrainian Medical Stomatological Academy

23 Shevchenka st., 36011 Poltava, Ukraine

tel: +380502165247

e-mail: tatapolishyk09@gmail.com

Received: 02.03 .2020

Accepted: 15.10 .2020

A - Work concept and design, B - Data collection and analysis, C - Responsibility for statistical analysis,

D-Writing the article, E-Critical review, $\mathbf{F}$ - Final approval of the article 